\title{
Exposure to Lead, Cadmium and Chromium among Spray Painters in Automobile Body Repair Shops
}

\author{
Banjong VitayavirasuK ${ }^{1}$, Supaporn Junhom $^{1}$ and Pitchaya TantisaeraneE ${ }^{2}$
}

${ }^{1}$ Faculty of Environmental Management, Prince of Songkla University and ${ }^{2}$ Department of Community Medicine, Faculty of Medicine, Prince of Songkla University, Thailand

\begin{abstract}
Exposure to Lead, Cadmium and Chromium among Spray Painters in Automobile Body Repair Shops: B. VitaYAVIRAsuk, et al. Faculty of Environmental Management, Prince of Songkla University, Thailand-Environmental and biological monitoring of lead, cadmium and chromium levels in spray painters is reported. All of the study subjects worked in automobile body repair shops that had no standard spraying room. They were divided into 2 groups, those who wore an aerosol-removing respirator while spraying $(n=20)$ and those who did not wear the respirator $(n=50)$. Air in the breathing zone of each subject was sampled and analyzed for lead, cadmium and chromium levels. The subjects' blood lead levels and urinary cadmium and chromium levels were also measured along with those of a control group. The mean environmental and biological levels of these metals between the two groups of the painters were not significantly different $(p>0.05)$. However, the biological levels of the metals were significantly higher in the study groups than in the control group $(p<0.01)$. On-site observations revealed that improper use of an aerosol-removing respirator, lack of an isolated spraying room and poor personal hygiene habits caused the failure to prevent heavy metal exposure among the automobile spray painters.

(J Occup Health 2005; 47: 518-522)
\end{abstract}

Key words: Lead, Cadmium, Chromium, Occupational exposure, Spray painters, Automobile spray painting

Automobile spray painting is among the jobs which are likely to result in exposure to heavy metals in the workplace. Lead, cadmium and chromium are major toxic metals which are found in automobile paints. They are components of paint pigments, such as lead chromate,

Received Sep 18, 2004; Accepted Jul 27, 2005

Correspondence to: B. Vitayavirasuk, Faculty of Environmental Management, Prince of Songkla University, Hat Yai, Songkhla, 90112, Thailand (e-mail: banjong.v@psu.ac.th) lead oxide, cadmium yellow, chrome yellow and chrome orange ${ }^{1-3)}$. As automobile paints are sprayed, these metal compounds are dispersed and suspended in the atmosphere long enough to be inhaled by paint sprayers. Long term exposure to lead can cause degeneration of the central nervous system (chronic encephalopathy), anemia and renal failure ${ }^{1)}$. Chronic exposure to airborne cadmium can cause obstructive lung disease and possibly lung cancer ${ }^{2}$. Long term exposure to cadmium via water and food can lead to renal tubular dysfunction, disturbance of calcium metabolism, osteoporosis and osteomalacia ${ }^{2)}$. Chronic inhalation of hexavalent chromium compounds may cause allergic asthmatic reaction, ulceration in the mucus membrane, perforation of the nasal septum and bronchial carcinoma ${ }^{3)}$.

Automobile body repair shops in Hat Yai City Municipality, Songkhla Province, Southern Thailand are generally small sized, with less than 10 workers. Use of an isolated spraying room is not strictly enforced in the shops, and therefore, most automobile spray painters work without isolated spraying rooms. It was reported previously that only $30 \%$ of them wore an aerosolremoving respirator when spraying paint ${ }^{4)}$. However, painters who used a respirator did not wear it while other workers were spraying paint nearby. It was doubtful whether spray painters who wore a respirator under such conditions received enough protection from toxic metal exposure. The objective of this study was to assess the exposure to lead, cadmium and chromium among automobile spray painters who wore a respirator only when spraying compared to exposure of the spray painters who did not wear any respirator at any time.

\section{Materials and Methods}

A cross-sectional study was undertaken. Seventy automobile spray painters were recruited to the study. All of them had been working at the job for at least 1 year and had no previous work related to heavy metals. The spray painters were divided into 2 groups: those who 
wore an aerosol-removing respirator while spraying $(n=20)$ and those who did not wear any respirator at work $(n=50)$. The respirators used by the subjects were those of half-mask, negative pressure air purifying type, equipped with high-efficiency particulate air (HEPA) filters ( $\mathrm{P}$ series) which can be used for trapping $99.97 \%$ of any $0.3 \mu \mathrm{m}$ or larger particulate contaminant. No fit test was done before the respirator was worn by each subject. Generally, the cartridge was changed once a year. A walk-through survey of each painter's workplace was conducted. A questionaire was used to interview each painter on risk behaviors related to exposure to heavy metals.

Environmental lead, cadmium and chromium exposure was monitored through a personal air sampling pump (pumping 1.5 liters of air per min) with an inlet attached to the shirt collar near the breathing zone of each painter during one eight-hour working day (full period single sampling). Mixed cellulose ester filters ( $37 \mathrm{~mm}$ diameter, $0.8 \mu \mathrm{m}$ pore size) were used to collect respirable dust. After the collection, the filters were digested with concentrated nitric acid (70\%) in a laboratory microwave oven (MDS 2000, CEM Corp, USA). The digested samples were diluted with ultrapurified water and were analysed for lead, cadmium and chromium concentrations in duplicate with a graphite furnace atomic absorption spectrophotometer (GFAAS) (Varian SpectrAA-800 GTA100, Varian, Australia), following the method described previously ${ }^{5}$.

Whole blood samples were collected from the spray painters. From each sample, one aliquot $(4 \mathrm{ml})$ was kept in an acid cleaned plastic test tube and was analysed for lead content with the GFAAS ${ }^{6}$. The other aliquot was immediately sent to the hematology laboratory for complete blood counts. Spot urine samples were also collected from the spray painters during a work shift. Care was taken to avoid contamination during sampling, including asking the subjects to take off their shirt and to wash their hands thoroughly with soap and water before urine collection. Each urine sample was divided into 2 portions. One portion was kept in an acid cleaned cup to which a few drops of concentrated nitric acid had been added to reduce the $\mathrm{pH}$ of the urine to less than 2. This portion was kept at $4^{\circ} \mathrm{C}$ until analyzed for cadmium and chromium contents with the GFAAS ${ }^{7}$. The other portion was kept in a plastic cup at $4^{\circ} \mathrm{C}$ and was sent to the clinical chemistry laboratory for measurement of creatinine concentration using a Hitachi 717 Autoanalyser (Boeringer Mannheim, Germany) (Jaffe method) ${ }^{8}$. The same procedure was also performed for a control group which included workers who had never had occupational exposure to heavy metals. These workers had similar socioeconomic status as the study subjects.

The health condition of the spray painters was evaluated through physical examination and the use of a questionnaire to establish their medical history.

\section{Validation of the Analyses}

Field blank samples and laboratory blank samples were used in all of the analyses as a quality control. A blood lead control, containing $9.99 \mu \mathrm{g} / \mathrm{dl}$ lead, was used as a reference material. The control was supplied by the Ministry of Public Health Department of Medical Science for quality assurance of the blood lead analysis. The coefficient of variation (CV), accuracy and detection limit of the blood lead analysis were $1.01 \%, 98.81 \pm 2.93 \%$ and $0.22 \mu \mathrm{g} / \mathrm{dl}$, respectively.

Urine metals controls (Bio-Rad Laboratories Limited, Germany) were used as reference materials for the urine analyses. The CV, accuracy and detection limit of the measurement of urinary cadmium levels were $1.10 \%$, $87.03 \pm 2.12 \%$ and $0.11 \mu \mathrm{g} / \mathrm{l}$, respectively. The CV, accuracy and detection limit of the measurement of urinary chromium levels were $6.22 \%, 95.96 \pm 12.97 \%$ and $0.38 \mu \mathrm{g} / \mathrm{l}$, respectively.

\section{Statistical Analyses}

Differences of the mean levels of lead, cadmium and chromium among the 3 groups were tested with the Kruskall-Wallis test. Differences of the mean levels of the metals between the groups were tested with the MannWhitney U test.

\section{Results}

Physical examination and medical histories of the automobile spray painters established that all of them had normal health conditions, except for three painters who experienced asthma. The histories and clinical profile of the painters along with those of the control group are shown in Table 1 . Note that $64.3 \%$ of the study subjects were smokers. The study subjects stated that the most frequently occurring symptoms which they had experienced over the previous year were symptoms of the digestive system, respiratory system, nervous system and musculoskeletal system (Table 2). The occurrences of these symptoms among the painters were found to be greater than those of the control group (Table 2).

Close observation of the spray painters' activities at work revealed that most of them did not use spray paint in an isolated room, and that those who wore a respirator did so only when they were spraying paint. They did not wear a respirator while other workers were spraying paint nearby. In addition, no fit test was done for each respirator. Some of the spray painters showed poor personal hygiene habits, such as eating food or smoking cigarettes in the workplace without washing their hands first, living at their workplace or returning home after work without taking a shower or changing into clean clothes. The frequencies of these risk behaviors are shown in Table 3. 
Table 1. History and clinical profile of the study subjects and the control group

\begin{tabular}{lcc}
\hline & Study Subjects & Controls \\
\hline Age (years old) & $27 \pm 7$ & $26 \pm 5$ \\
$\quad$ Less than 20 years old & 12 & 11 \\
21-30 years old & 39 & 42 \\
31-40 years old & 16 & 15 \\
more than 40 years old & 3 & 2 \\
Sex (\% male) & 100 & 100 \\
Weight (kg) & $56 \pm 9$ & $57 \pm 7$ \\
Height (cm) & $166 \pm 7$ & $168 \pm 6$ \\
Work duration (yr) & $8.3 \pm 5.6$ & $7.8 \pm 5.3$ \\
Smokers (\%) & 64.3 & 31.4 \\
Non-smokers (\%) & 35.7 & 68.6 \\
Education (\%) & & \\
$\quad$ 6th grade & 60.0 & 54.3 \\
$\quad$ 9th grade & 24.3 & 25.7 \\
12th grade & 15.7 & 20.0 \\
Blood pressure (mm Hg) & & $120 \pm 13$ \\
$\quad$ Upper level & $121 \pm 12$ & $68 \pm 11$ \\
$\quad$ Lower level & $66 \pm 12$ & $72 \pm 13$ \\
Heart rate (time/min) & $77 \pm 14$ & $44 \pm 2$ \\
Hematocrit (\%) & $44 \pm 3$ & $15.1 \pm 1.0$ \\
Hemoglobin (g/dl) & $14.5 \pm 1.2$ & \\
\hline
\end{tabular}

Table 2. Occurrences of symptoms among the automobile spray painters compared with those of the control group

\begin{tabular}{lcc}
\hline \multicolumn{1}{c}{ Symptoms } & \multicolumn{2}{c}{ Frequency (\%) } \\
\cline { 2 - 3 } & Study Subjects & Control \\
\hline Digestive System & & \\
$\quad$ Dry mouth & 54.3 & 32.4 \\
Sore throat & 54.3 & 20.3 \\
Constipation & 30.0 & 21.6 \\
Respiratory System & & \\
Nasal congestion & 44.3 & 32.4 \\
Sneezing & 38.6 & 24.3 \\
Phlegm discharge & 34.3 & 17.5 \\
Nasal irritation & 32.9 & 8.1 \\
Cough & 30.0 & 18.9 \\
Asthma & 4.3 & 1.4 \\
Musculoskeletal System & & \\
Muscle pain & 44.3 & 24.3 \\
Joint pain & 34.3 & 13.5 \\
Muscle cramp & 30.0 & 18.9 \\
Tremor & 30.0 & 14.8 \\
Nervous System & & \\
Poor co-ordination & 35.7 & 10.8 \\
Numbness of extremities & 32.9 & 14.8 \\
Insomnia & 30.0 & \\
\hline & &
\end{tabular}

The average working atmospheric levels of lead of the two groups of spray painters were less than the TLVTWA value for lead chromate $\left(0.05 \mathrm{mg} / \mathrm{m}^{3}\right)$ recommended by $\mathrm{ACGIH}^{9)}$ (Table 4). There was no significant difference in the mean environmental lead levels and blood lead levels between the two groups of spray painters ( $>0.05$ ). The mean blood lead levels of the two groups were significantly higher than the control group $(\mathrm{p}<0.01)$, but were nevertheless below the regulatory limit ( $40 \mu \mathrm{g} /$ dl) set by the 1993 US Occupational Safety and Health Administration (OSHA) ${ }^{1)}$.

The mean urinary cadmium levels of the two groups of the spray painters were also significantly higher than that of the control group $(\mathrm{p}<0.01)$ (Table 4$)$, but were still less than the regulatory limit set by OSHA $(3 \mu \mathrm{g} / \mathrm{g}$ creatinine $)^{2)}$. The mean environmental and urinary cadmium levels between the two groups of the spray painters were not significantly different $(p>0.05)$ although one value of the environmental cadmium levels from the non-protected group exceeded the time weighted average permissible exposure limit $\left(5 \mu \mathrm{g} / \mathrm{m}^{3}\right)^{9}$.

The mean environmental and urinary chromium levels of the two groups of the spray painters were less than the standard allowances $\left(100 \mu \mathrm{g} / \mathrm{m}^{3}\right.$ and $10 \mu \mathrm{g} / \mathrm{g}$ creatinine, respectively $)^{9,10)}$. The mean environmental and urinary chromium levels between the two groups of the spray painters were not significantly different ( $p>0.05)$. However, the urinary chromium levels of the two groups 
Table 3. Frequencies of the study subjects' risk behaviors

\begin{tabular}{lc}
\hline & $\%$ \\
\hline - Not wearing a respirator while spraying & 72.8 \\
- Not wearing protective clothing at work & 91.4 \\
- Eating food or drinking water without washing hands first & 87.2 \\
- & 30.0 \\
- Noting food or drinking water without washing face first & 74.3 \\
- No separate laundry for clothes worn at work & 20.0 \\
- Living at the workplace & 85.7 \\
\hline
\end{tabular}

Table 4. Environmental and biological levels of lead, cadmium and chromium in two groups of automobile spray painters and the control group. Values are shown as mean \pm standard deviation with range values in parentheses

\begin{tabular}{|c|c|c|c|c|c|c|c|}
\hline Group & $\mathrm{n}$ & $\begin{array}{c}\text { Working } \\
\text { Atmospheric } \\
\text { Lead }\left(\mu \mathrm{g} / \mathrm{m}^{3}\right)\end{array}$ & $\begin{array}{l}\text { Blood Lead } \\
\qquad(\mu \mathrm{g} / \mathrm{dl})\end{array}$ & $\begin{array}{c}\text { Working } \\
\text { Atmospheric } \\
\text { Cadmium }\left(\mu \mathrm{g} / \mathrm{m}^{3}\right)\end{array}$ & $\begin{array}{c}\text { Urinary } \\
\text { Cadmium }(\mu \mathrm{g} / \mathrm{g} \\
\text { creatinine })\end{array}$ & $\begin{array}{c}\text { Working } \\
\text { Atmospheric } \\
\text { Chromium }\left(\mu \mathrm{g} / \mathrm{m}^{3}\right)\end{array}$ & $\begin{array}{c}\text { Urinary } \\
\text { Chromium }(\mu \mathrm{g} / \mathrm{g} \\
\text { creatinine })\end{array}$ \\
\hline $\begin{array}{l}\text { Painters wearing } \\
\text { a respirator }\end{array}$ & 20 & $\begin{array}{l}0.97 \pm 1.73 \\
(0.08-5.75)\end{array}$ & $\begin{array}{c}8.62 \pm 2.72 * \\
(3.54-14.10)\end{array}$ & $\begin{array}{c}0.01 \pm 0.01 \\
(\mathrm{nd}-0.02)\end{array}$ & $\begin{array}{c}0.57 \pm 0.26^{*} \\
(0.15-1.05)\end{array}$ & $\begin{array}{l}0.73 \pm 0.83 \\
(0.31-3.07)\end{array}$ & $\begin{array}{c}0.87 \pm 0.54 * \\
(0.19-2.44)\end{array}$ \\
\hline $\begin{array}{l}\text { Painters not wearing } \\
\text { a respirator }\end{array}$ & 50 & $\begin{array}{l}0.62 \pm 1.30 \\
(0.05-5.60)\end{array}$ & $\begin{array}{c}10.42 \pm 4.07 * \\
(5.27-26.00)\end{array}$ & $\begin{array}{c}0.30 \pm 1.28 \\
(\mathrm{nd}-5.74)\end{array}$ & $\begin{array}{c}0.76 \pm 0.54 * \\
(0.29-3.42)\end{array}$ & $\begin{array}{l}0.64 \pm 0.50 \\
(0.25-2.55)\end{array}$ & $\begin{array}{c}1.25 \pm 0.88 * \\
(0.11-3.90)\end{array}$ \\
\hline Control & 30 & N/A & $\begin{array}{l}4.24 \pm 1.25 \\
(2.33-6.50)\end{array}$ & N/A & $\begin{array}{c}0.12 \pm 0.09 \\
(\text { nd- }-0.30)\end{array}$ & N/A & $\begin{array}{c}0.17 \pm 0.16 \\
(\mathrm{nd}-0.67)\end{array}$ \\
\hline
\end{tabular}

* significantly different from the control group $(\mathrm{p}<0.01)$. nd=not detectable. N/A=not applicable.

were significantly higher than those of the control group $(\mathrm{p}<0.05)$ (Table 4).

\section{Discussion}

Many chemicals used by automobile spray painters, especially those in organic solvents, can elicit respiratory injuries by acting as nonspecific irritants or by stimulating immune-mediated mechanisms ${ }^{11)}$. Most of the clinical symptoms reported in this study were predominately related to exposure to organic solvents and certain organic chemicals rather than to heavy metal exposure (Table 1). For example, some of the spray painters had asthma, of which the most common cause is a group of chemicals, isocyanates, found in organic solvents ${ }^{11)}$. Other symptoms which were partly related to solvent and certain organic chemical exposure include sore throat, nasal irritation, cough, sneezing, phlegm discharge, and symptoms of the nervous system ${ }^{11}$. However, constipation, insomnia and numbness of arms and legs might be partly related to heavy metal exposure ${ }^{12}$. Smoking cigarettes was also a possible confounder in this study since there were more smokers in the study subjects than in the control group (Table 1). Smoking cigarettes has been linked to exposure of the three metals and many symptoms observed in this study ${ }^{1-3)}$.

Spot urine samples instead of 24-h urine samples were collected in this study because routine collection of 24-h urine samples from the workers was impractical ${ }^{13)}$. Greater variation of the amount of the analytes was expected. However, creatinine adjustment was used for correction in cases of concentrated or diluted samples. Lead was determined in blood instead of in urine because lead in blood is considered to be the best indicator of recent exposure ${ }^{13)}$. Lead in urine fluctuates with time more than lead in blood and there is usually a poor association between lead in urine and lead in blood ${ }^{13)}$. We did not analyze zinc protoporphyrin (ZPP) in whole blood and delta-aminolevulinic acid (ALA) in urine because of their limited specificity and/or sensitivity and their different time responses following lead exposure ${ }^{13)}$. In addition, there is no guideline values for these biomarkers for occupationally exposed subjects. However, these two biomarkers are important when interpreting blood lead levels clinically ${ }^{13)}$.

As expected there was no significant difference of working atmospheric levels of lead, cadmium and 
chromium between the spray painters who wore a respirator and those who did not (Table 4) because the measurements were taken outside the respirator for those who wore a respirator when spraying. Therefore, the data did not indicate the quantities of the metals breathed in by the study subjects, but only indicated the quantities of the metals suspended in the surrounding air.

Though the average biological levels of lead, cadmium and chromium were lower in the spray painters who wore a respirator than those who did not, there were no significant differences in any of these levels between the two groups ( $p>0.05)$. It could be argued that the sample size of the subjects who wore a respirator was too small to be bcompared with the other group, but the sample size was the highest number we could get from the whole population within the study area.

Note that the standard urinary chromium value cited from the ACGIH biological exposure indices (BEI) is actually applied only to water-soluble chromium VI fume as generated in welding operations. There is no BEI for chromate pigments which are water-insoluble chromium VI. The low urinary chromium levels seen in this study might represent a higher exposure but poorer bioavailability.

The study revealed that all the spray painters did not use a respirator properly. No fit test was done before a respirator was worn, whenever a different respirator was used, and at least annually thereafter. There was no schedule for cleaning, inspecting, and repairs. There was no training of workers concerning the hazards to which they are potentially exposed and how to use the respirator effectively.

Another important protection that was found lacking for the study subjects was an isolated spraying room with a properly designed and installed ventilation system. This room must be used in conjunction with a proper respirator in order to lower contaminant concentrations to acceptable levels and to limit the spreading of the contaminants. However, most automobile body repair shops seen in this study had at least 2 sides opened for good ventilation resulting in less accumulation of heat and low levels of the air pollutants targeted in this study. Finally, the poor personal hygiene habits shown by the study subjects could increase their risk of exposure to the heavy metals and negate the protective effect of a respirator.

In conclusion, improper use of an aerosol-removing respirator, lack of an isolated spraying room and poor personal hygiene habits resulted in failure to prevent toxic metal exposure among automobile spray painters. On the job training of standard procedures, good personal hygienic practice, and increased risk awareness and health perception among the workers are recommended.
Acknowledgment: This research was supported by the Royal Thai Government Annual Research Budget and the Graduate School at Prince of Songkla University.

\section{References}

1) Keogh JP and Boyer LV. Lead. In: Sullivan Jr JB, Krieger GR, eds. Clinical environmental health and toxic exposures. Philadelphia: Lippincott Williams \& Wilkins, 2001: 879-889.

2) Waalkes MP, Wahba ZZ and Rodriguez RE. Cadmium. In: Sullivan Jr JB, Krieger GR, eds. Clinical environmental health and toxic exposures. Philadelphia: Lippincott Williams \& Wilkins, 2001: 889-897.

3) Langård $\mathrm{S}$ and Norseth T. Chromium. In: Friberg L, Nordberg GF, Vouk VB, eds. Handbook on the toxicology of metals. 2nd ed. Amsterdam: Elsevier Science Publishers BV, 1986: 185-210.

4) B Vitayavirasuk, W Keowkarnkah and P Tantiseranee: A survey on health problems of welders, painters and nightclub workers in Hat Yai District, Songkhla Province. Songkla Med J 11, 47-55 (1993)

5) Beach LM: Varian SpectrAA Zeeman graphite furnace methods for environmental samples. Springvale:Varian Techtron Pry Ltd, 1989: 1-6.

6) C Flajnik and D Shrader: Determination of lead in blood by GFAAS-deuterium and Zeeman background correction. Varian AA 110, 1-5 (1993)

7) TS Steven, AG Zoe and RC Glen: The determination of chromium and cadmium in urine by graphite furnace atomic absorption. Atomic Spectroscopy 17, 225-228 (1996)

8) K Spencer: Analytical reviews in clinical biochemistry: the estimation of creatinine. Ann Clin Biochem 23, 125 (1986)

9) Doull J. Recommended limits for occupational exposure to chemicals. In: Klaassen CD, ed. Casarett and Doull's Toxicology. 6th ed. New York: McGrawHill, 2001: 1155-1176.

10) American Conference of Governmental Industrial Hygienists. 2001 Threshold limit values for chemical substances and physical agents and biological exposure indices. Cincinnati: ACGIH, 2001.

11) Gordon PE and Chiang WK. Painters and furniture refinishers. In: Greenberg MI, Hamilton RJ, Phillips SD, McCluskey GJ, eds. Occupational, industrial, and environmental toxicology. 2nd ed. Philadelphia: Mosby, 2003: 284-291.

12) Kazantzis G. Diagnosis and treatment of metal poisoning—general aspects. In: Friberg L, Nordberg GF, Vouk VB, eds. Handbook on the toxicology of metals. 2nd ed. Vol. I: general aspects. Amsterdam: Elsevier Science Publishers BV, 1986: 294-318.

13) Lauwerys, RR and Hoet, P. Industrial chemical exposure : Guidelines for biological monitoring. 3rd ed. Boca Raton: Lewis Publishers, 2001. 